was initiated, and this was a policy that required an infectious diseases physician to approve the use of cefotaxime (the major cephalosporin used at the hospital). Vancomycin use also required the same type of approval, and the use of clindamycin also was restricted because of an outbreak of Clostridium difficile colitis that was occurring at the same time.

After 6 months, the average monthly use of cefotaxime, ceftazidime, vancomycin, and clindamycin had decreased by $84 \%, 55 \%, 34 \%$, and $80 \%$, respectively; the point prevalence of fecal colonization with VRE decreased from $47 \%$ to $15 \%$, and the number of patients whose clinical specimens were culture-positive for VRE also decreased gradually. The authors concluded that the change in antibiotic use appeared to have affected the VRE outbreak when previous measures had failed.

FROM: Quale J, Landman D, Guillermo S, et al. Manipulation of a hospital antimicrobial formulary to control an outbreak of vancomycin-resistant enterococci. Clin Infect Dis 1996;23:1020-1025.

\section{Bacterial Contamination of Dental Unit Water Lines}

In Canada, the current public health standards consider water to be safe for consumption when it contains a total bacterial count of less than $500 \mathrm{CFU} / \mathrm{mL}$ and is free of coliform bacteria. However, as most water microbiologists have known for years, the gram-negative water bacteria can grow quite well in water, and, in doing so, form biofilms and thus colonize water distribution pipes. This ecosystem offers a never-ending supply of gram-negative bacteria in the water. For the most part, ingestion of water containing this group of bacteria does not cause disease in humans. However, the introduction of these bacteria into open lesions, such as one experiences in a dental unit, has caused concern. Researchers from the dental school at the University of Montreal, Quebec, Canada, conducted a study that was designed to observe bacterial colonization of dental unit water lines from a dynamic standpoint through multilevel analysis and species identification, distribution, and fluctuation in number over time. Water samples were collected from 123 dental units at the dental school, and 30 of the units were included in a multilevel analysis that consisted of samples taken at the beginning of the workday and after a 2-minute purge, and quantitative assays were performed and isolates identified.

Among the results were: the highest colony counts were achieved using R2Am medium (a reduced nutrient medium) at $22^{\circ} \mathrm{C}$, as compared to TSA and blood agar at $37^{\circ} \mathrm{C}$; the colony counts reached a plateau after 7 days. At the beginning of the workday, the air-water syringes and highspeed water lines contained water with counts over 100,000 $\mathrm{CFU} / \mathrm{mL}$, and, after a 2-minute purge, the counts were reduced by approximately 2 logs. The predominant bacterial species recovered were characteristic gram-negative water bacteria, such as Sphyngomonas paucimobilis, Acinetobacter calcoaceticus, Methylobacter mesophilicum, and Pseudomonas aeruginosa. Dental units contaminated by $P$ aeruginosa had the highest total bacterial counts; $P$ aeruginosa never was isolated from the tap water feeding the dental units.

The authors concluded that dental unit water lines should be considered an aquatic ecosystem in which opportunistic pathogens successfully colonize the water pipes, increasing the concentration of bacteria to potentially dangerous levels Although the clinical significance is yet to be documented, a number of techniques for purging or disinfecting the systems are suggested.

FROM: Barbeau J, Tanguay R, Faucher E, et al. Multiparametric analysis of waterline contamination in dental units. Appl Environ Microbiol 1996;62:3954-3959.

\section{APHA Addresses Contaminated Dental Unit Water Lines}

Bacterial contamination of dental unit water lines has been a continuing subject that has been discussed by the Microbial Contamination Control Committee of the American Public Health Association's (APHA) Laboratory Section. The committee met during the meetings of the APHA, November 17-21, in New York City. The committee has a keen and ongoing interest in microbial contamination associated with medical devices that are difficult to clean and thus renders such devices difficult to sterilize or disinfect. In the case of dental unit water lines, the committee has drafted a policy statement for endorsement by the APHA to encourage the dental community to realize that dental unit water lines can be contaminated excessively with gram-negative water bacteria. Because many of these can be potential pathogens, the committee urges that purging and disinfection procedures be done routinely. 